05

\title{
Зависимость структуры ионно-модифицированных слоев монокристаллов NiTi от ориентации облучаемой поверхности
}

\author{
() Т.М. Полетика, ${ }^{1}$ Л.Л. Мейснер, ${ }^{1,2}$ С.Л. Гирсова, ${ }^{1}$ А.В. Твердохлебова, ${ }^{1}$ С.Н. Мейснер ${ }^{1,2}$ \\ ${ }^{1}$ Институт фозики прочности и материаловедения СО РАН, \\ 634055 Томск, Россия \\ ${ }^{2}$ Национальный исследовательский Томский государственный университет, \\ 634036 Томск, Россия \\ e-mail: poletm@ispms.tsc.ru
}

(Поступило в Редакцию 17 ноября 2015 г. В окончательной редакции 25 октября 2016 г.)

\begin{abstract}
Методами оже-электронной спектроскопии и просвечивающей электронной микроскопии исследованы состав и структура имплантированных $\mathrm{Si}-$ слоев монокристаллов никелида титана, различно ориентированных относительно направления ионно-пучкового воздействия. Выявлена роль „мягкой“ $[111]_{\text {в2 и „жесткой“ }}$

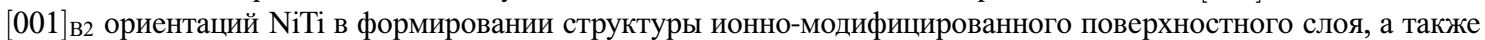
дефектной структуры приповерхностных слоев монокристаллов. Обнаружены ориентационные эффекты селективного распыления и каналирования ионов, контролирующие состав и толщину формирующихся оксидного и аморфного слоев, глубину проникновения ионов и примесей, а также концентрационный профиль распределения $\mathrm{Ni}$ на поверхности.
\end{abstract}

DOI: $10.21883 /$ JTF.2017.07.44672.1663

\section{Введение}

Никелид титана, обладающий эффектом памяти формы и сверхэластичностью, является материалом, широко используемым в медицине [1]. Актуальной является задача создания на поверхности NiTi протективных слоев, которые обладают улучшенными эксплуатационными свойствами и минимизируют высвобождение токсичного для организма $\mathrm{Ni}$ [2]. Одним из способов модификации поверхности NiTi является ионная имплантация, позволяющая создавать ионно-легированные слои с высокой биосовместимостью, коррозионной и усталостной стойкостью и другими важными характеристиками $[3,4]$. Анализ литературы показывает, что наибольшее внимание уделяется изучению поверхностных слоев NiTi с точки зрения их функциональных свойств. В то же время ограничено число работ, в которых рассмотрены вопросы механизмов формирования сложной градиентной структуры ионно-модифицированных слоев. Основной трудностью, возникающей перед исследователями, безусловно, является многофакторность и взаимозависимость явлений, одновременно происходящих в поверхности материала в процессе воздействия ионами.

В последнее время в связи с эксплуатацией малоразмерных систем медицинского назначения внимание исследователей привлекает фактор кристаллографической анизотропии NiTi [5-8]. Известно [9], что существуют „мягкие“ (близкие к полюсу $\langle 111\rangle)$ и „жесткие“ (полюс $\langle 001\rangle)$ ориентации относительно оси деформации. В В2-аустените „мягкие“ кристаллы отличаются от „жестких“ более низкими величинами сопротивления скольжению, а в интервале мартенситных превращений - величинами критического напряжения мартенситного сдвига. При эксплуатации текстурированных тонкостенных трубок или проволок упругопластиче- ская анизотропия может приводить к неоднородности напряженно-деформированного состояния, сильной локализации деформации с последующим разрушением. При этом „слабым звеном“ (в зависимости от условий эксплуатации) могут служить как наиболее трудные для деформации кристаллы [001], так и зерна типа [111] [5,6].

Результаты исследований влияния ориентации кристаллов (зерен) NiTi на структуру и свойства модифицированного слоя на их поверхности носят ограниченный характер. Можно отметить работу [10], в которой методом дифракции обратнорассеянных электронов исследована структура приповерхностных слоев поликристаллического $\mathrm{NiTi}$ после ионного легирования Si. Обнаружена зависимость фрагментации зерен от их кристаллографической ориентации по отношению к направлению падающего пучка ионов, причем быстрее фрагментируются зерна, в которых кристаллографическая ориентация семейств плотноупакованных плоскостей $\{111\},\{112\}$ близка направлению ионно-пучкового воздействия. Представленные в [10] результаты позволяют говорить о зависимости деформационного отклика зерен на нагружение от кристаллографического направления высокоэнергетического воздействия.

В настоящей работе для получения новых данных о процессах, происходящих в структуре поверхности при ионно-пучковом воздействии, используется исследование облученных монокристаллов NiTi. Задачами работы являются:

1) исследование структуры поверхностных слоев монокристаллов NiTi после ионной модификации,

2) выявление роли ориентации монокристалла в формировании сложной градиентной структуры ионно-модифицированного слоя и в изменении дефектной структуры приповерхностного слоя материала. 


\section{1. Материалы и методы исследований}

Исследования проводили на монокристаллах $\mathrm{Ti}-$ 50.6 at.\% $\mathrm{Ni}(0.3$ at.\% $\mathrm{Fe}$ и 0.3 at.\% Мо) в В2-состоянии. Температуры начала и конца прямого и обратного превращений составляли: $M_{s}=260 \mathrm{~K}, M_{f}=249 \mathrm{~K}$, $A_{s}=271 \mathrm{~K}, A_{f}=299 \mathrm{~K}$. Использовали образцы монокристаллов с „мягкими“ (близкие к полюсу $\langle 111\rangle$ ) и „жесткими“ (полюс $\langle 001\rangle$ ) ориентациями относительно направления ионного пучка, совпадающего с нормалью к поверхности образца (ось $Z$ ). Ориентации образцов определяли на рентгеновском дифрактометре „ДРОН-7“ (Буревестник). Проводили кристаллографический анализ на основе специально разработанных программных алгоритмов обработки экспериментальных данных. Так, установлено, что точными кристаллографическими индексами нормали $Z$ к поверхности „жесткого“ монокристалла являются $\left[\begin{array}{lll}1 & 1 & 14\end{array}\right]_{\text {В2 }}$ (угол с $[001]_{\text {В2 }}$ составляет $\left.5.7^{\circ}\right)$, а к поверхности „мягкого“ монокристалла $\left[\begin{array}{lll}5 & 5 & 7\end{array}\right]_{\text {В2 }}$ (угол с $[111]_{\text {В2 }}$ составляет $9.5^{\circ} \mathrm{C}$ ). Далее по тексту для монокристаллов приводятся обозначения $[001]_{\mathrm{B} 2}$ и $[111]_{\mathrm{B} 2}$ соответственно.

Поверхности образцов перед облучением подготавливали в несколько этапов:

1) химическое травление в растворе кислот (3 части $\mathrm{HNO}_{3}+1$ часть $\left.\mathrm{HF}\right)$,

2) механическая шлифовка до „зеркального блеска“ на шлифовальном станке Saphir 550 (ATMGMBH, Германия) с последовательным уменьшением размера частиц абразива до $(1.2-0.3) \mu \mathrm{m}$,

3) электролитическая полировка в растворе кислот (3 части $\mathrm{CH}_{3} \mathrm{COOH}+1$ часть $\mathrm{HClO}_{4}$ ).

В результате поверхности различно ориентированных кристаллов не отличались по качеству, что подтверждалось методом просвечивающей электронной микроскопии (ПЭМ). Ионное легирование проводили на ионном имплантере „ДИАНА-З“ (ИФПМ СО РАН) с применением импульсных пучков ионов $\mathrm{Si}$ с флюенсом $D=6 \cdot 10^{17} \mathrm{~cm}^{-2}$ при среднем значении ускоряющего напряжения $60 \mathrm{kV}$ с длительностью импульсов ионного тока $250 \mu \mathrm{s}$ и частотой следования импульсов $50 \mathrm{~Hz}$. Остаточное давление в рабочей камере составляло $3 \times 10^{-3} \mathrm{~Pa}$. Температура образца в процессе ионной обработки не превышала $473 \mathrm{~K}$. Структурные исследования проводили в ЦКП „НАНОТЕХ“ ИФПМ СО РАН. Использовали метод ПЭМ на микроскопе JEM 2100 (JEOL). Тонкие фольги в геометрии „cross-section“ готовили ионным утонением на установке EM 09100IS (JEOL). Для послойного элементного анализа поверхности образцов использовали методом оже-электронной спектроскопии (ОЭС) на спектрометре „Шхуна-2“ (НИТПУ, Россия). Энергетическое разрешение анализатора составляло $0.7 \%$. Для послойного распыления материала мишени использовали пучок ионов аргона с энергией ионов $3 \mathrm{keV}$, скорость распыления материала мишени составляла $2-3 \mathrm{~nm} / \mathrm{min}$.

\section{2. Результаты исследований}

\section{1. Концентрационные профили распределения элементов}

На рис. 1 представлены концентрационные профили распределения элементов в поверхностных слоях образцов монокристаллов после имплантации $\mathrm{Si}$ для образцов ориентаций $[111]_{\text {В2 }}$ и $[001]_{\text {B2 }}$. На поверхности имплантированных сплавов на основе Ті всегда присутствует наружный поверхностный оксидный слой [4]. Для монокристаллов NiTi независимо от ориентации в него входят атомы $\mathrm{C}$ и $\mathrm{O}$, адсорбированные на поверхности из остаточной атмосферы вакуумной камеры ионного имплантера.

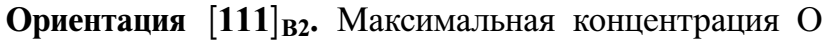
и $\mathrm{Ti}$ в оксидном слое достигает 55 и 30 at.\% соответственно (рис. $1, a$ ), что соответствует почти стехиометрическому диоксиду титана $\mathrm{TiO}_{2}$. По мере удаления вглубь от поверхности концентрация кислорода падает и остается в пределах 5 at.\% на протяжении всего ионномодифицированного слоя. Из рис. $1, a$ следует, что максимальная концентрация имплантируемого $\mathrm{Si}$ достигает 15 at.\% внутри оксидного слоя. Отметим, что положения максимумов концентраций $\mathrm{O}$ и $\mathrm{Si}$ (рис. $1, a$ ) совпадают по глубине, т.е. атомы кремния локализованы в области максимальной концентрации атомов кислорода, что предполагает образование в поверхностном оксидном слое также оксидов $\mathrm{Si}$. Концентрационный профиль $\mathrm{Ni}$ в результате обеднения данным элементом поверхности смещен на глубину оксидного слоя (рис. $1, a$ ), далее концентрация Ni резко увеличивается от 0 до 56 at.\%.

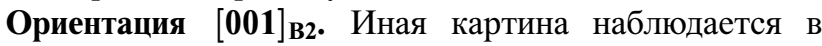
образце $[001]_{\text {В2 }}$ (рис. $1, b$ ): концентрационный профиль $\mathrm{Si}$ не выражен и его наличие в поверхностном слое идентифицируется лишь по перегибам на дифференциальных спектрах (рис. 1, c). Представление оже-спектров в дифференциальном виде бывает необходимым в случае, когда концентрация элементов мала и слабые пики сливаются с фоном [11]. На дифференциальных спектрах (рис. $1, c)$ слабый оже-сигнал для $\mathrm{Si}$ становятся выраженным в виде перегибов, а сигнал для $\mathrm{Ni}-$ в виде двухполярного пика. Атомы кислорода также присутствуют в ионно-модифицированном слое в концентрации примерно 10 at.\% (рис. 1,b). Для сравнения средняя концентрация $\mathrm{O}$ на аналогичной глубине поверхности

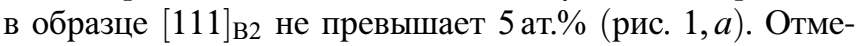
тим, что концентрационный профиль $\mathrm{Ni}$ также смещен на глубину оксидного слоя, однако концентрация $\mathrm{Ni}$ в

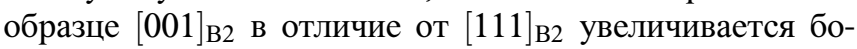
лее плавно от значений, близких к 5 at.\%, на поверхности до 50 at.\% к середине ионно-модифицированного слоя (рис. $1, a$ ). В целом глубина обеднения поверхности $\mathrm{Ni}$ в поверхностном слое образца $[001]_{\text {В2 }}$ почти в 2 раза меньше, чем для $[111]_{\mathrm{B} 2}$.

Таким образом, в имплантированных слоях образца

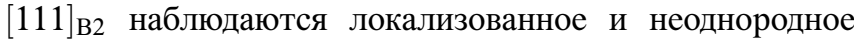
распределения элементов, в то время как для образца 

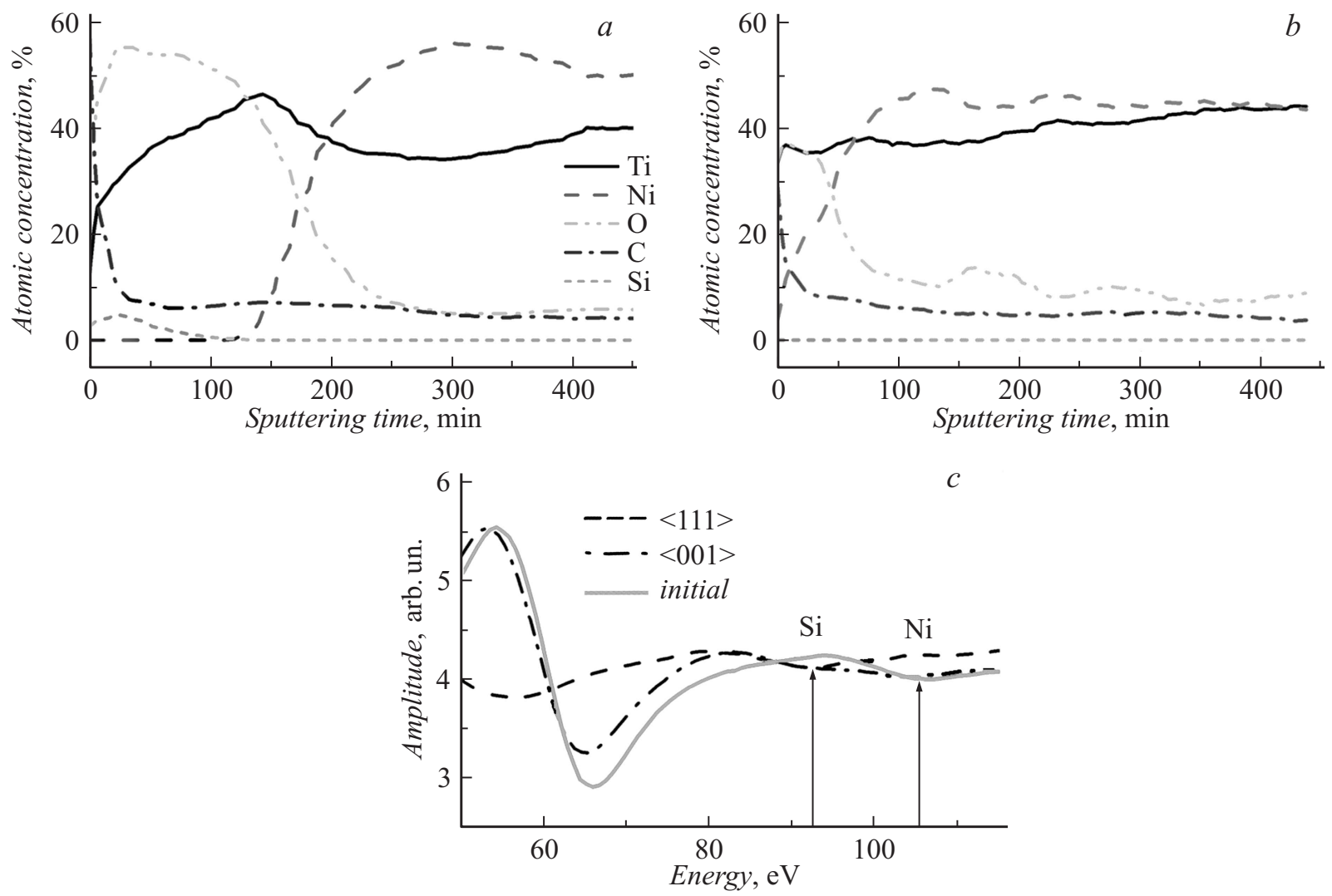

Рис. 1. Концентрационные профили распределения элементов по глубине, полученные для образцов монокристаллов NiTi c различной ориентацией относительно ионного пучка $\mathrm{Si}$ : ориентация $[111]_{\text {в2 }}(a)$; ориентация $[001]_{\text {в2 }}(b)$; оже-электронные спектры распределения Si и Ni в дифференциальном виде, по оси ординат - амплитуда в условных единицах $(c)$.

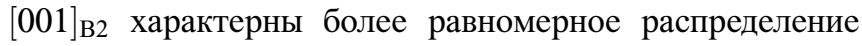
компонентов сплава и более глубокое проникновение имплантируемых ионов и примесей.

\section{2. Структура поверхностных слоев}

Исследование структуры поверхностных слоев монокристаллов NiTi методом ПЭМ показало (рис. 2), что после ионно-пучковой обработки $\mathrm{Si}$ формируется хорошо обособленный ионно-модифицированный слой, в котором можно выделить два основных подслоя: 1) наружный оксидный слой, 2) аморфный ионно-модифицированный слой. Между ионно-модифицированным аморфным слоем и основным материалом присутствует пограничный подслой с повышенной дефектностью.

Оксидный слой. ПЭМ изображения наружных поверхностных слоев (пленок) образцов монокристаллов $[111]_{\mathrm{B} 2}$ и $[001]_{\mathrm{B} 2}$ можно видеть на рис. $2, a, b$ соответственно. Оксидный слой для монокристаллов обеих ориентаций имеет толщину 10-20 nm. Отметим, что для $[111]_{\text {В2 }}$ средняя толщина оксидного слоя почти в

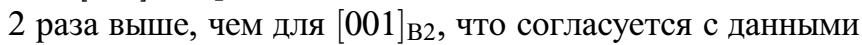
ОЭС. На рис. 3,a приведены картины электронной микродифракции для монокристаллов $[111]_{\mathrm{B} 2}$ и $[001]_{\mathrm{B} 2}$, которые получены с дифракционной площади до $200 \mathrm{~nm}$, захватывающей одновременно оксидный и аморфный слои. Микродифракция демонстрирует диффузное гало, свойственное аморфному слою, а также содержат серию колец из отдельных рефлексов, относящихся к оксидному слою, что свидетельствует о выделении нанокристаллитов окислов размером до $10 \mathrm{~nm}$. Возможно образование оксидов $\mathrm{TiO}_{2}$ и $\mathrm{SiO}_{2}$ стехиометрического или близкого к нему состава, при этом в наружных слоях монокристаллов обеих ориентаций преобладают нанокристаллы $\mathrm{TiO}_{2}$. Статистически надежных количественных данных об объемных долях различных оксидов в настоящей работе не получено. Нанодифракционный анализ с диаметром зонда около $15 \mathrm{~nm}$ позволил установить, что $\mathrm{TiO}_{2}$ встречается в фазовых модификациях брукида и рутила, а $\mathrm{SiO}_{2}-$ в модификациях $\alpha$-кварца и низкотемпературного тридимита с параметрами решетки $a=18.524, b=5.003, c=23.810, \beta=105.82$. На рис. $3, b$ приведен пример расшифровки картины нанодифракции для двух соседних частиц оксидов Ті и $\mathrm{Si}$ (рис. 3,c). Отметим, что оксиды титана и кремния существуют в виде отдельных фаз, что связано с их низкой взаимной растворимостью в твердом состоянии [12]. Доказательств существования фаз кремния с титаном и никелем, а также карбидов не обнаружено.

Аморфный ионно-модифицированный слой. Аморфную структуру слоя характеризует диффузное гало, соответствующее отражению аустенита $\{110\}$, что свиде- 


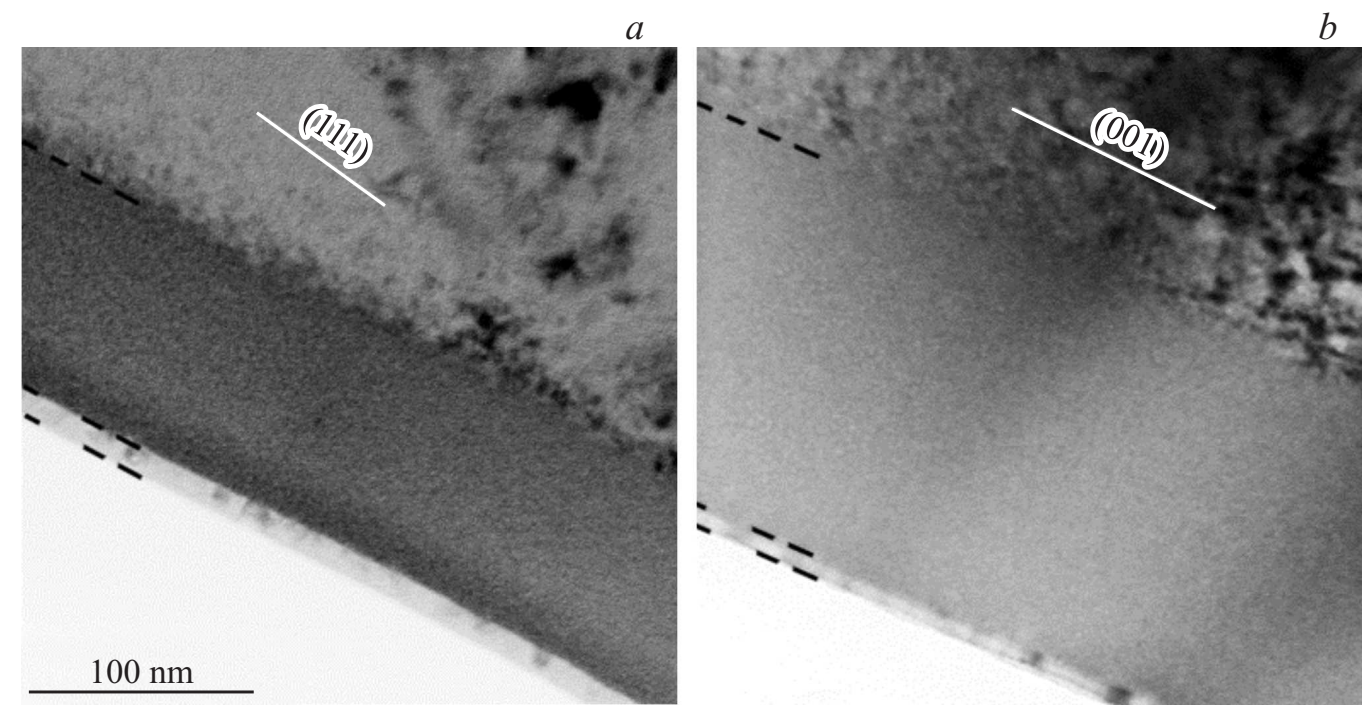

Рис. 2. Светлопольное ПЭМ изображение поверхностных слоев монокристаллов NiTi, имплантированных $\mathrm{Si}$, с ориентациями $[111]_{\mathrm{B} 2}(a)$ и $[001]_{\mathrm{B} 2}(b)$ относительно направления ионно-пучкового воздействия. Фольги получены в геометрии „сross-section“.
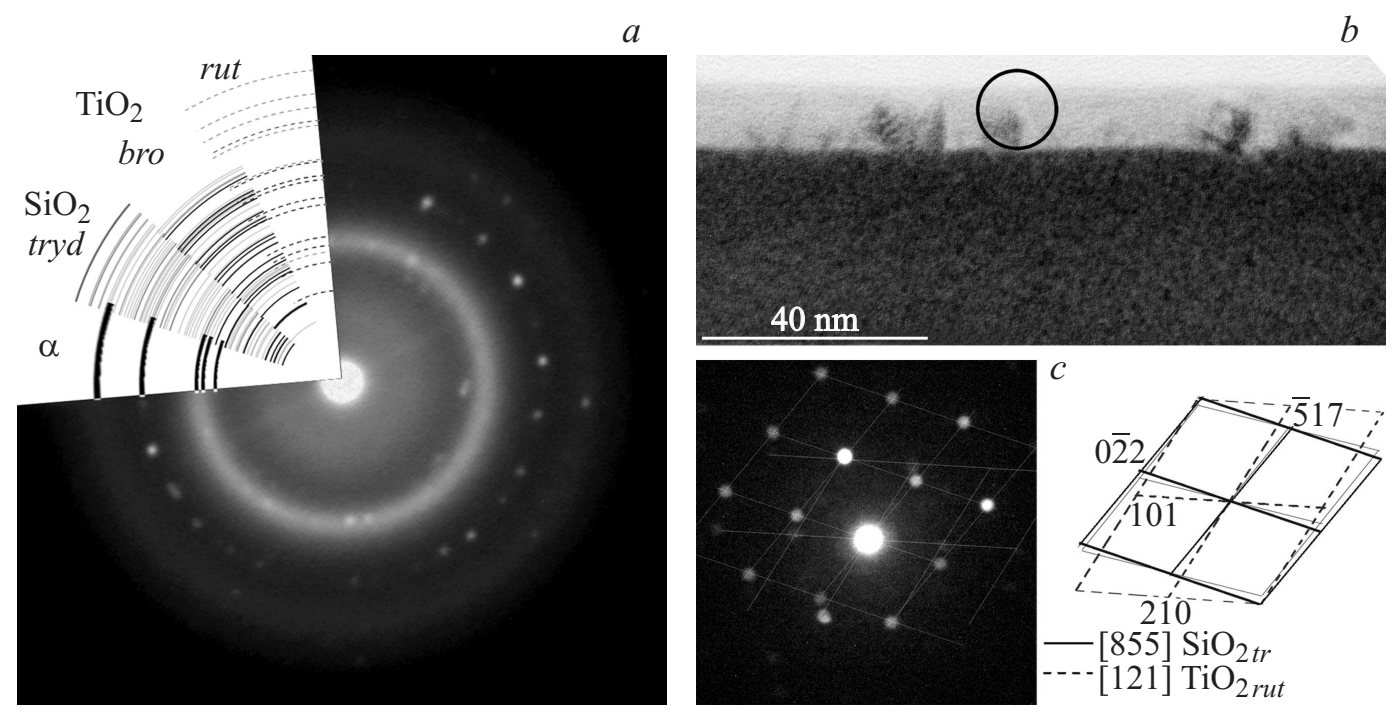

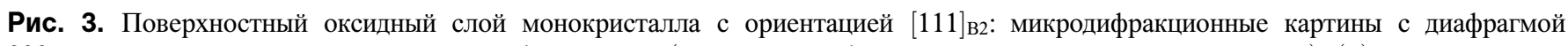
$200 \mathrm{~nm}$, охватывающей оксидный и аморфный слои (кольцевые рефлексы относятся к оксидному слою) (a); светлопольное ПЭМ изображение оксидного слоя $(b)$; нанодифракционная картина с диаметром зонда около $15 \mathrm{~nm}$ с выделенной на рис. 3 , а области и соответствующая схема расшифровки $(c)$.

тельствует о существовании ближнего позиционного порядка атомов в аморфном состоянии. Для монокристалла ориентации $[111]_{\text {в2 }}$ аморфный слой имеет толщину около $100 \mathrm{~nm}$ (рис. 2,a). Следует отметить неоднородность сорбционного контраста внутри аморфного слоя, которая позволяет разделить его по глубине на две зоны: ближе к поверхности находится более темный слой толщиной 30-50 nm. Согласно сорбционному контрасту для аморфного материала [13], в темном слое локализован более тяжелый элемент, в нашем случае - Ni. Это подтверждается данными количественного энергодисперсионого анализа по характеру изменения отношения концентрации атомов Ті и $\mathrm{Ni}$ (рис. $4, a$ ). О неоднородном распределении $\mathrm{Ni}$ по глубине аморфного слоя также могут свидетельствовать результаты исследования методом ПЭМ в режиме нанодифракции (диаметр зонда до $30 \mathrm{~nm})$. Так, показано, что для ближайшего к поверхности темного слоя (область 1 , рис. $4, a$ ) диффузное гало более широкое (рис. 4,b) по сравнению с центром аморфного слоя (область 2, рис. 4,a) и характеризуется неоднородной структурой, содержащей множество слабых и „размытых“ рефлексов (рис. 4,c). Ширина гало соответствует изменению межатомных расстояний в пределах $1.85-2.44 \mathrm{~nm}$, причем уширяется оно в сторону больших углов отражения, что свидетельствует об уменьшении межатомных расстояний. Это может быть 

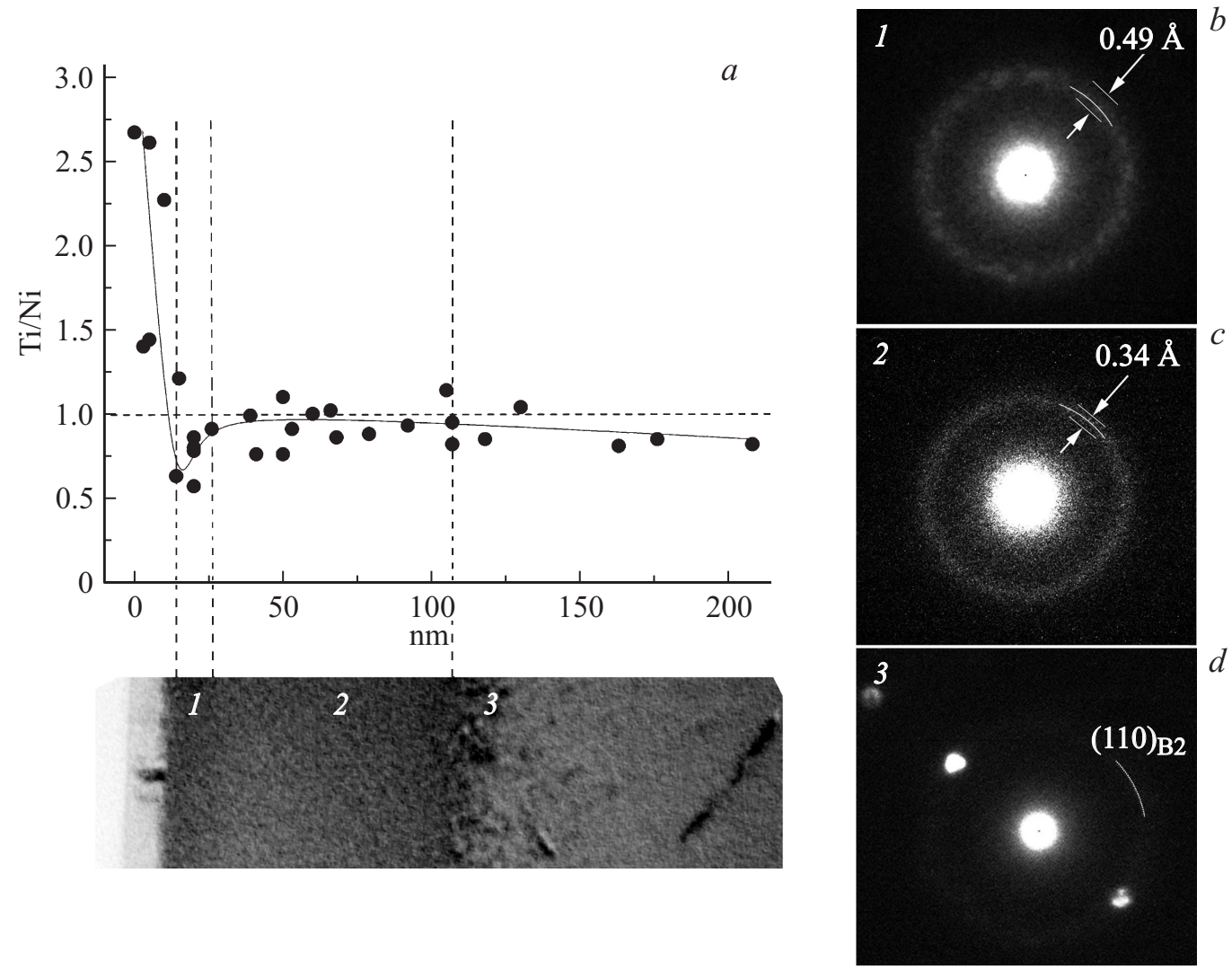

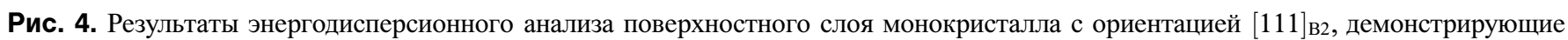
изменение относительного содержания Тi и Ni с глубиной и совмещенные с соответствующим светлопольным ПЭМ изображением $(a)$; картины нанодифракции (диаметр зонда $\leq 30 \mathrm{~nm}$ ), с областей $1-3$ соответственно $(b)$, (дугой отмечено положение отражения $\{110\}_{\mathrm{B} 2}$, указана средняя ширина диффузного гало).

связано с ростом содержания атомов $\mathrm{Ni}$ в результате их диффузии от поверхности и аккумуляции в областях с меньшим содержанием кислорода $[4,14]$.

На границе ионно-модифицированного аморфного слоя и материалом-основой можно выделить тонкий дефектный подслой, характеризующийся неоднородным контрастом (область 3, рис. 4, $a$ ). Известно, что переходный слой служит местом локализации различных дефектов, образующихся в ходе имплантации (точечных дефектов, дислокационных петель, дислокационных скоплений и др.), а также возможного выделения нанофаз преимущественно на основе основных компонентов сплава $[4,15]$. Косвенным свидетельством реализации такого рода процессов может служить изменение параметров решетки в рассматриваемом подслое. Так, анализ картин нанодифракции (диаметр зонда $15 \mathrm{~nm}$ ), снятых с шагом около $15 \mathrm{~nm}$, показал, что от границы аморфного слоя на глубину до $50 \mathrm{~nm}$ происходит постепенное уменьшение межплоскостных расстояний $\{110\}$ от значения $2.169 \mathrm{~nm}$, соответствующего эквиатомному составу NiTi, до значения $2.128 \mathrm{~nm}$, характерного для исходного состояния NiTi. Подобное изменение может быть связано с возникновением концентрационных неоднородностей по $\mathrm{Ni}$, в том числе нанофаз с повышенным его содержанием. О концентрационном расслоении может свидетельствовать также расщепление рефлекса $g=110$ на картине нанодифракции (рис. 4, $d$ ), полученной непосредственно под аморфным слоем.

Следует отметить, что для образца с ориентацией

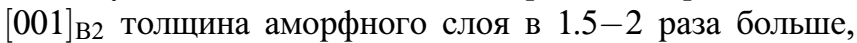
чем для кристалла с ориентацией $[111]_{\text {в2. Микроди- }}$ фракционная картина с аморфного слоя характеризуется однородным и узким диффузным кольцом $\{110\}$.

Приповерхностные слои. Характерная микрострукту-

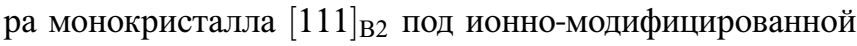
поверхностью представлена на рис. 5, а. Ближайший к облучаемой поверхности слой глубиной до $2 \mu \mathrm{m}$ отличается низкой плотностью прямолинейных дислокаций и дислокационных петель, что может быть результатом процессов возврата во время ионно-пучковой обработки. Другой особенностью данного подслоя является наличие фазы со структурой R-мартенсита, что однозначно выявляется из картины микродифракции на рис. 5, $а$. Появление R-фазы связывают со сдвигом температурного интервала превращений и подавлением образования фазы В19' в тонких приповерхностных слоях при имплантации $[4,14]$.

В целом на глубине от $200 \mathrm{~nm}$ до $10 \mu \mathrm{m}$ наблюдается разнообразная картина, однако основной закономерностью является наличие следов протекания прямых, а 

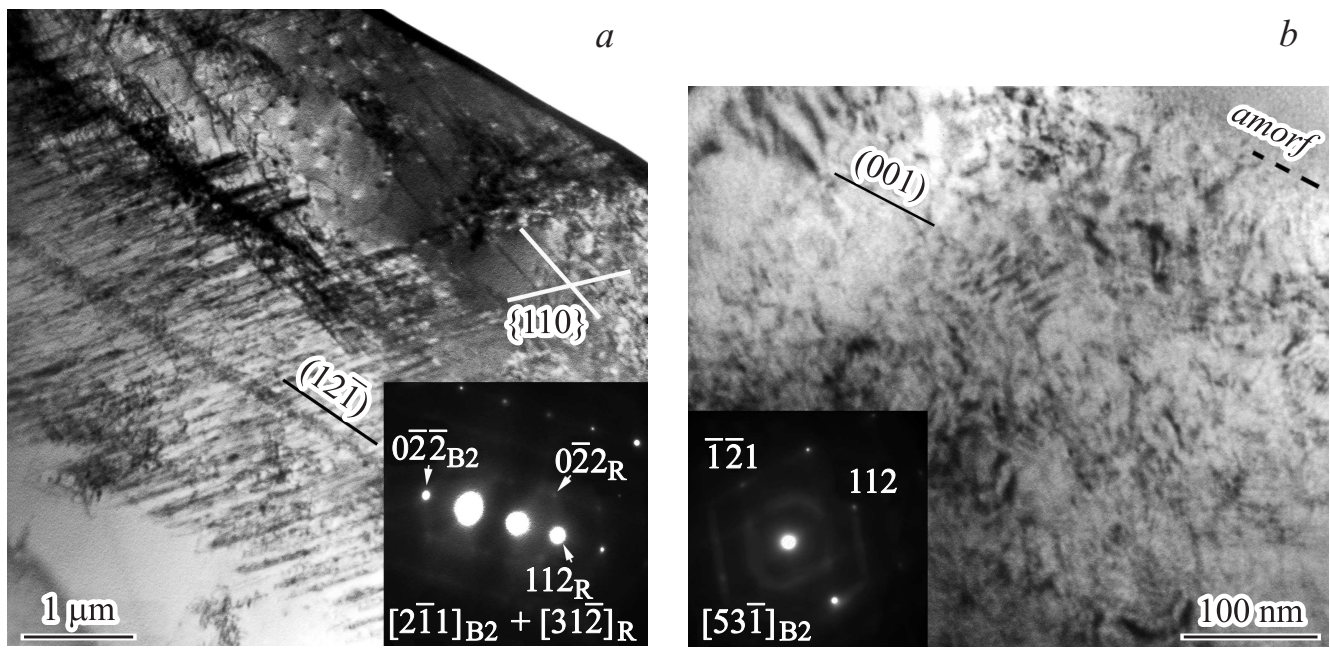

Рис. 5. Микроструктура приповерхностных слоев монокристаллов NiTi с ориентациями $[111]_{\mathrm{B} 2}(a)$ и $[001]_{\mathrm{B} 2}(b)$ относительно направления ионно-пучкового воздействия.

затем обратных мартенситных превращений В19' $\leftrightarrow$ В2. Это проявляется в наличии полос локализации дислокационной плотности вдоль следов плоскостей $\{112\}$ и $\{110\}$, которые также являются плоскостями габитуса мартенситных пластин, а также вдоль границ бывших мартенситных двойников внутри пластин $[15,16]$. Основным признаком подобной структуры является формирование стенок из вытянутых дислокационных петель, образованных, согласно [15], в результате скольжения по системам (101) [010] ОЦК решетки, которое вызвано высокими внутренними напряжениями, возникающими внутри мартенситных пластин. Подобные образования формируют характерную структуру, называемую „fishbone“ и могут наблюдаться в сплавах NiTi после обработки ионным пучком $[15,16]$.

Особенностью кристалла $[001]_{\mathrm{B} 2}$ является наличие непосредственно под аморфным слоем повышенной плотности дислокаций (до $10^{14} \mathrm{~m}^{-2}$ ), которые образуют мелкосетчатую структуру с узлами сетки, закрепленными дислокационными петлями либо наночастицами. На глубине до $10 \mu \mathrm{m}$ картина достаточно неоднородна, однако наиболее характерным является возникновение в приповерхностном слое полос локализованной деформации (рис. 6). Отметим, что деформационные полосы имеют непрерывные разориентировки с матрицей, при этом не наблюдается субграниц, что позволяет говорить о формировании полос переориентации, вытянутых преимущественно параллельно ионно-модифицированной поверхности вдоль плоскостей $\{100\}$ с разворотом вокруг оси [110]. Кристаллографический анализ с использованием ряда полученных картин микродифракции (рис. 6) позволил рассчитать набор углов разворота между мезополосами вокруг направления $[110]_{\text {в2. Так, }}$ переориентация возрастает по направлению к поверхности облучения (рис. 6 , области $1-3$ ). Разориентации между областями 1,2 и 3 составляют: между 1 и $2-$ $6.2^{\circ}$, между 2 и $3-15.9^{\circ}$, между 3 и $1-22.05^{\circ}$.
Наблюдаемое разбиение кристалла на ряд областей с переориентированной решеткой является одним из механизмов ротационной деформации, реализуемых в „жестких“ кубических кристаллах в условиях отсутствия возможности легкого скольжения [17].

\section{3. Обсуждение результатов}

Полученные результаты показали, что на поверхности монокристаллов NiTi после ионно-пучкового воздействия формируется сложная градиентная структура, содержащая два основных подслоя: наружный оксидный слой и ионно-модифицированный аморфный слой. Это согласуется с данными ряда авторов, полученных ранее для имплантированных поликристаллов $\mathrm{NiTi}[4,14,18]$.

Возникновение поверхностного нанокристаллического керамического оксидного слоя, его состав и рост толщины определяются условиями имплантации [4]. Как оказалось, при одинаковом режиме ионной имплантации данный процесс зависит от ориентации поверхности монокристаллов NiTi относительно направления ионного пучка. Так, относительное содержание оксидов $\mathrm{Ti}$ и $\mathrm{Si}$ на поверхности определяется характером распределения имплантируемого $\mathrm{Si}$ в глубь кристаллов (рис. 1). Следует отметить, что создание поверхностных нанокерамических слоев, содержащих смесь оксидов $\mathrm{TiO}_{2}$ и $\mathrm{SiO}_{2}$, повышает биосовместимость, нетоксичность и другие функциональные свойства титана и сплавов на его основе [19].

Важным параметром, характеризующим состояние оксидных слоев, является содержание в них $\mathrm{Ni}$. Глубина и форма концентрационных профилей для данного элемента свидетельствуют о существенном влиянии ориентации поверхности монокристалла NiTi относительно ионного пучка на характер распределения Ni в поверхностных слоях (рис. $1, a, b)$. Так, для ориентации $[111]_{\mathrm{B} 2}$ 


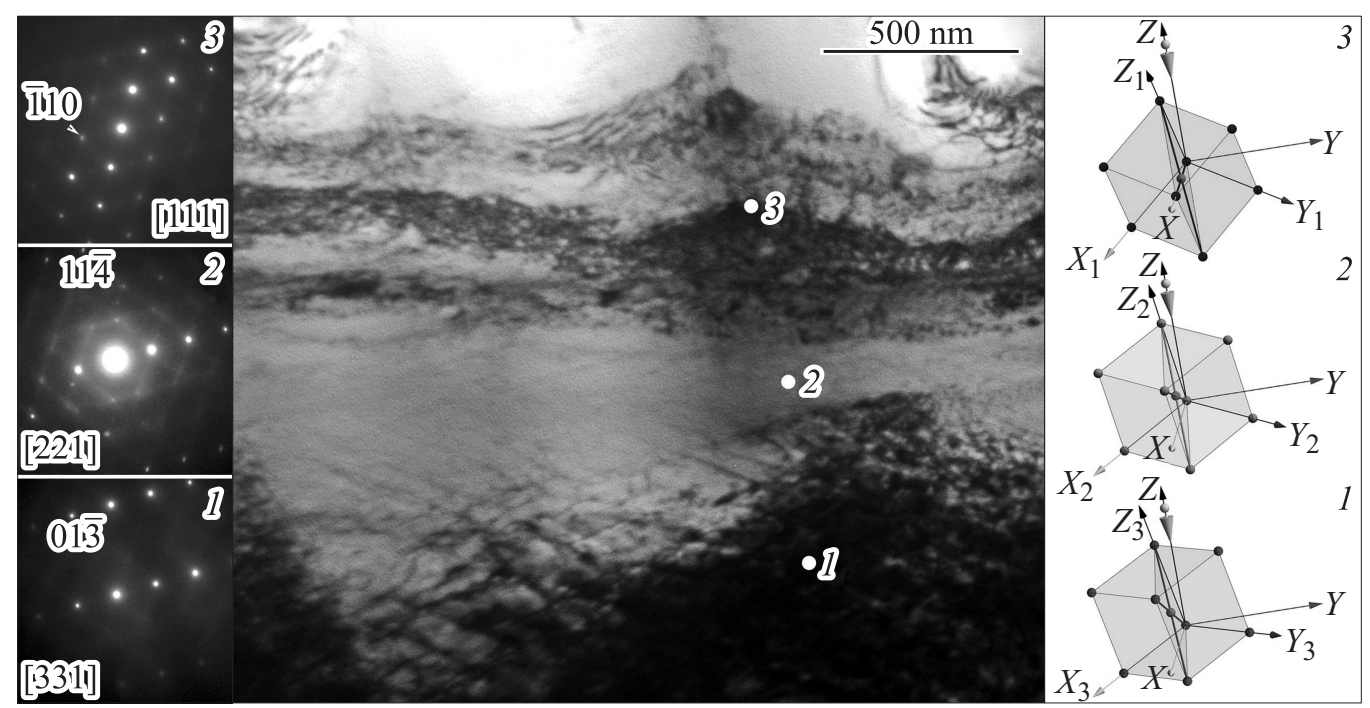

Рис. 6. Микроструктура приповерхностного слоя монокристалла с ориентацией $\langle 114\rangle_{\mathrm{B} 2}$, близкой $\langle 001\rangle_{\mathrm{B} 2}$, после ионнопучковой обработки (глубина около $10 \mu \mathrm{m})$. Представлены микродифракционные картины и указаны пространственные ориентации элементарных ячеек В2-структуры соседних областей кристалла относительно внешней системы координат. Области кристалла 1 , 2 и 3 пронумерованы по направлению к поверхности образца. Разориентации вокруг оси, соответствующей $\approx[\overline{1} 10]$, между областями 1,2 и 3 составляют: между 1 и $2-6.2^{\circ}$; между 2 и $3-15.9^{\circ}$; между 3 и $1-22.05^{\circ}$.

наблюдается отсутствие $\mathrm{Ni}$ на глубину оксидного слоя. К факторам, определяющим данный эффект, относят: a) процесс предпочтительного распыления атомов $\mathrm{Ni}$, для которых скорость распыления в 3 раза выше, чем для $\mathrm{Ti}$, б) более сильные связи $\mathrm{Ti}-\mathrm{O}, \mathrm{Si}-\mathrm{O}$ по сравнению с $\mathrm{Ni}-\mathrm{O}[14,18]$. Это характерно для состава имплантированных поверхностных слоев поликристаллического NiTi [4,14,18]. Благодаря диффузии $\mathrm{Ni}$ от поверхности его атомы аккумулируются в областях с меньшим содержанием кислорода, при этом максимум локализации Ni находится около границы оксид-ионномодифицированный слой, что в настоящей работе подтверждается данными ПЭМ (рис. 4).

Иная картина наблюдается в случае ориентации

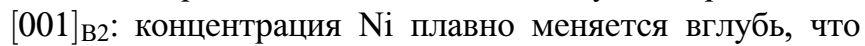
демонстрирует меньшую потерю Ni (рис. 1, b). Учитывая одинаковые условия ионной обработки, наблюдаемый эффект может быть объяснен дополнительным влиянием на коэффициенты распыления анизотропии кристалла. Известно, что минимумам коэффициента распыления соответствуют такие направления пучка относительно кристалла, вдоль которых кристаллическая решетка имеет наибольшую прозрачность, т.е. направления, параллельные либо осям, либо плоскостям мишени с низкими кристаллографическими индексами [20]. Такому

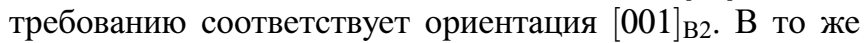
время следствием низкого коэффициента распыления

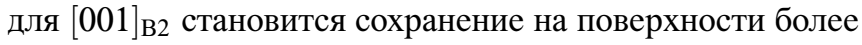
высокой концентрации $\mathrm{Ni}$.

Ориентация поверхности облучения существенно влияет на структуру формирующегося аморфного ионномодифицированного слоя монокристаллов NiTi (рис. 2). Несмотря на то что вопрос о возможных механизмах твердофазной аморфизации NiTi при высокодозном ионном облучении остается дискуссионным [21], наиболее вероятной причиной считается накопление радиационных точечных дефектов после прохождения каскадов атомных смещений (КАС) до концентрации выше критической, которая делает более выгодным аморфное состояние $[4,21,22]$. Упорядоченный интерметаллидный сплав NiTi относят к классу аморфных веществ дисторсионного типа, при котором коагуляция аморфных областей в КАС сопровождается незначительным химическим разупорядочением и сохранением ближнего позиционного порядка. Это проявляется в сохранении на дифракционных картинах отражения $\{110\}$. Искажения в аморфном NiTi, обусловленные радиационными дефектами, составляют около $0.2 \AA$, т. е. находятся в масштабах элементарной ячейки NiTi [22].

Рассмотрим особенности аморфного состояния, формирующегося при имплантации $\mathrm{Si}$ монокристаллов различной ориентации. Так, по данным ОЭС поверхностный аморфный слой для ориентации $[111]_{\text {в2 отличается }}$ неоднородным распределением компонентов сплава и примесей, в том числе локализацией атомов Ni. Это может приводить к значительным искажениям аморфной структуры, связанным, во-первых, с накоплением примесей из адсорбированного наружного слоя (уширение гало $\{110\})$, во-вторых, с образованием слоя, обогащенного $\mathrm{Ni}$, сопровождающимся уменьшением межатомных расстояний (смещение гало от положения $\{110\}$ в сторону меньших углов). Таким образом, имеет место структурная неоднородность аморфного состояния с перепадами плотности и элементного состава.

Для имплантированного образца с ориентацией [001] характерно однородное и узкое диффузное кольцо $\{110\}$, 
что свидетельствует о более совершенной структуpe аморфного ионно-модифицированного слоя. Ионномодифицированный слой образца $[001]_{\mathrm{B} 2}$, согласно данным ОЭС, отличается более равномерным распределением компонентов сплава и более глубоким проникновением имплантируемых ионов и примесей по сравнению с кристаллом $[111]_{\mathrm{B} 2}$. Полагаем, что наблюдаемое отличие является следствием каналирования ионов [23]. Для ОЦК структуры NiTi благоприятной для каналирования является ориентация монокристалла типа [100], при которой атомные плоскости $\{100\}$ перпендикулярны к направлению потока внедряемых ионов. Каналирование способствует более глубокому проникновению ионов, активации процессов диффузии как основных компонентов, так и примесей в глубь кристалла, сдерживает излишнюю локализацию имплантируемых элементов в поверхностных слоях. Нельзя исключать взаимосвязи двух специфических эффектов, обнаруженных в настоящей работе, - ориентационной зависимости скорости распыления и каналирования. Это подтверждают результаты недавней работы [24] по исследованию имплантированной поверхности крупнозернистого сплава $\mathrm{Ni}$, в которой установлена возможность согласованного протекания рассматриваемых процессов.

Ориентационно-зависимым оказался и процесс формирования дефектной микроструктуры приповерхностных слоев исследуемых монокристаллов. Существенный объем дилатации при формировании ионно-модифицированного слоя, как правило, приводит к появлению упругих сжимающих напряжений в приповерхностном слое [4]. Для $\mathrm{NiTi}$, обладающего упругопластической анизотропией, данный эффект проявился в различном деформационном отклике на нагружение монокристаллов „мягкой“ $[111]_{\mathrm{B} 2}$ и ,жесткой“ $[001]_{\mathrm{B} 2}$ ориентаций на глубину до $10 \mu \mathrm{m}$. Так, для „мягкой“ ориентации характерно протекание прямых и обратных В2 $\leftrightarrow$ В19', либо В2 $\leftrightarrow \mathrm{R}$-превращений, что согласуется с данными о деформационном поведении монокристаллов ориента-

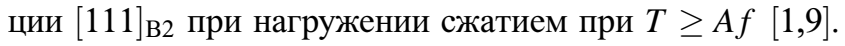

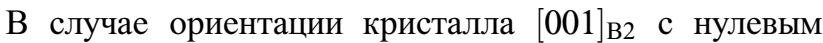
фактором Шмида для основной системы скольжения $\langle 100\rangle\{110\}$ реализуется формирование трехмерной сетчатой структуры с высокой плотностью дислокаций и узлами, закрепленными преимущественно дислокационными петлями. Достижение высокого уровня напряжений в упрочненном дислокационном слое может способствовать снижению сдвиговой устойчивости В2-структуры и появлению полос локализованной деформации на большей глубине $(\approx 10 \mu \mathrm{m})$. При этом важным фактом, обнаруженным в работе, является переориентация полос, возрастающая по направлению к поверхности облучения, что свидетельствует о коллективном характере процесса и реализации ротационной деформации [24]. Необходимые для этого условия задаются наличием неоднородного напряженного состояния и отсутствием возможности легкого скольжения. Следует отметить, что ротационная деформация является необратимым процессом и может сопровождаться преждевременным разрушением материала. Таким образом, релаксационная способность NiTi в приповерхностных слоях оказывается наименее эффективной в наиболее трудных для мартенситных превращений кристаллах $[001]_{\text {В2. }}$

\section{Заключение}

Исследованы закономерности влияния ориентации монокристаллов NiTi на формирование структуры поверхностного ионно-модифицированного слоя в процессе ионно-пучковой обработки. Установлена зависимость характера распределения имплантируемых ионов, компонентов сплава и примесей по глубине ионно-модифицированного слоя от ориентации относительно ионнопучкового воздействия.

Обнаружены специфические эффекты взаимодействия ионных пучков с поверхностью монокристаллов NiTi: ceлективное распыление и каналирование. Обнаруженные ориентационные эффекты контролируют толщину оксидного и аморфного слоев, глубину проникновения ионов и примесей, распределение $\mathrm{Ni}$ с глубиной. В аморфном

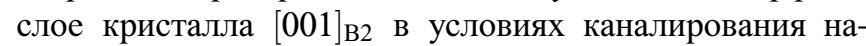
блюдается увеличение толщины в $1.5-2$ раза по сравнению с кристаллом $[111]_{\text {в2, }}$ сдерживание локализации имплантируемых элементов и примесей за счет их более глубокого проникновения в глубь кристалла.

Установлена ориентационная зависимость микроструктуры приповерхностных слоев, характеризующей деформационный отклик материала приповерхностных слоев монокристаллов NiTi на ионно-пучковое воздействие. Реализуются два сценария релаксации напряжений, возникающих около границы раздела аморфного слоя и материала-основы. Так, для „мягкой“ ориентации характерна реализация прямых и обратных В2 $\leftrightarrow$ В19'либо В2 $\leftrightarrow \mathrm{R}$-превращений. В наиболее трудных для мартенситных и дислокационных превращений кристаллах $[001]_{\mathrm{B} 2}$ возникают коллективные эффекты, проявляющиеся в формировании полос переориентации.

Работа выполнена в рамках Программы фундаментальных научных исследований государственных академий наук на 2013-2020 гг (проект 23.2.1).

\section{Список литературы}

[1] Otsuka K., Ren X. // Prog. Mater. Sci. 2005. Vol. 50. P. 511-678.

[2] Liu X., Chu P.K., Ding C. // Mater. Sci. Eng. R. 2010. Vol. 70. P. 275-302.

[3] Rautray T.R., Narayanan R., Kim K.-H. // Prog. Mater. Sci. 2011. Vol. 56. P. 1137-1177.

[4] Pogrebnjak A.D., Bratushka S.N. // Russ. Chem. Rev. 2013. Vol. 82. P. $1135-1159$.

[5] Schaffer J.E. // J. Mater. Eng. Perform. 2009. Vol. 18. P. 582-587.

[6] Barney M.M., Xub D., Robertson S.W. et al. // J. Mech. Behav. Biomed. Mater. 2011. Vol. 4. P. 1431-1439. 
[7] Pfetzing-Micklich J., Somsen C., Dlouhy A. et al. // Acta Mater. 2013. Vol. 61. P. 602-616.

[8] Jiang S., Hu L., Zhao Y., Zhang Y., Liang Y. // Mater. Sci. Eng. A. 2013. Vol. 569. P. 117-123.

[9] Gall K., Sehitoglu H., Chumlyakov Y.I., Kireeva I.V. // Acta Mater. 1999. Vol. 47. P. 1189-1214.

[10] Meisner S.N. // Russ. Phys. J. 2014. Vol. 57. P. 403-410.

[11] Анализ поверхности методами оже- и рентгеновской фотоэлектронной спектроскопии / Под ред. Д. Бриггса и М.П. Сиха. М.: Мир, 1984. 600 с.

[12] Rahmel A., Spencer P. // Oxid. Met. 1991. Vol. 35. P. 53-68.

[13] Spens J.C.Y. High-resolution Electron Microscopy. NY: Oxford University Press, 2003. 403 p.

[14] Kucharski S., Levintant-Zayonts N., Luckner J. // Mater. Des. 2014. Vol. 56. P. 671-679.

[15] Schmidt B. // Radiat. Eff. Defects Solids. 2007. Vol. 162. P. $171-184$.

[16] Norfleet D.M., Sarosi P.M., Manchiraju S. et al. // Acta Mater. 2009. Vol. 57. P. 3549-3561.

[17] Владимиров В.И., Романов А.Е. Дисклинации в кристаллах. Л.: Наука, 1986. 224 с.

[18] Tan L., Crone W.C. // Acta Mater. 2002. Vol. 50. P. 4449-4460.

[19] Tokarský J., Čapková P. // Appl. Surf. Sci. 2013. Vol. 284. P. $155-164$

[20] Sputtering of multicomponent materials. R. Behrisch (eds). Berlin: Springer-Verlag, 1983. $488 \mathrm{p}$.

[21] Коротаев А.Д., Тюменщев А.Н. // Изв. вузов. Физика. 1994. № 8. C. 3-30.

[22] Parkhomenko V.D., Dubinin S.F. // Phys. Metals Metallogr. 2012. Vol. 113. P. 641-662.

[23] Carnera A., Gasparotto A., Berti M., Fabbri R. // Microchim. Acta 1994. Vol. 114. P. 205-211.

[24] Saraf L.V. // Methods Phys. Res., Sect. B // 2015. Vol. 349. P. $193-200$. 